\title{
Improved Thermal Cyclability of Tertiary Battery Made of Prussian Blue Analogues
}

\author{
Izumi Takahara $^{[\mathrm{a}]}$, Assistant Prof. Takayuki Shibata*[a], Yuya Fukuzumi ${ }^{[\mathrm{b}]}$, and Prof. Yutaka
} Moritomo*[c]

\begin{abstract}
Tertiary battery is charged by the environmental heat, not by the electric energy, by using the difference $(\Delta \alpha)$ in the thermal coefficient $(\alpha=\mathrm{d} V / \mathrm{d} T)$ of redox potential $(V)$ between the anode and cathode materials. The thermal cyclability is not good in the prototypical $\mathrm{Na}_{x} \mathrm{Co}\left[\mathrm{Fe}(\mathrm{CN})_{6}\right]_{0.71}(\mathrm{NCF} 71) / \mathrm{Na}_{x} \mathrm{Co}\left[\mathrm{Fe}(\mathrm{CN})_{6}\right]_{0.90}$ (NCF90) tertiary battery. Here, we significantly improved the thermal cyclability of the tertiary battery with using Ni-substituted $\mathrm{Na}_{x} \mathrm{Ni}\left[\mathrm{Fe}(\mathrm{CN})_{6}\right]_{0.68}$ (NNF68). The Ni-substituted NNF68/NCF90 tertiary battery shows good thermal cyclability: both the cell voltage and capacity essentially unchanged up to the 10th thermal cycles.
\end{abstract}

\section{Introduction}

An innovative energy harvesting technology, which converts waste heat near room temperature and/or human body heat to electric energy at low cost and high efficiency, is required to realize a smart society. Recently, several researchers ${ }^{[1]}$ reported that the environmental heat can put a battery in a charged state by using the difference $(\Delta \alpha)$ in the thermal coefficient $(\alpha=\mathrm{dV} / \mathrm{d} T)$ of the redox potential $(V)$ between the anode and cathode materials. Hereafter, we call the battery "tertiary battery", because it is charged by the environmental heat, not by the electric energy. The tertiary battery generates electric energy in the thermal cycle between low $\left(T_{\mathrm{L}}\right)$ and high $\left(T_{\mathrm{H}}\right)$ temperatures. In the warming process, the battery shows the cell voltage $\left(V_{\text {cell }}\right)$ of $\Delta \alpha \Delta T$ ( $\Delta T=$ $T_{\mathrm{H}}-T_{\mathrm{L}}$ ) and the accumulated electric energy can be extracted by discharging the cell at $T_{\mathrm{H}}$. Similarly, the cooling process induces $V_{\text {cell }}(=-\Delta \alpha \Delta T)$. From a thermodynamically point of view, $\alpha$ is nothing but $\Delta S / e$, where $e$ and $\Delta S$ are the elementary charge (>

[a] I. Takahara and Assistant Prof. T. Shibata Gumma College

National Institute of Technology

Maebashi, Gumma, 371-8530, Japan shibata@nat.gunma-ct.ac.jp

[b] Y. Fukuzumi (JSPS Research fellow) Graduate School of Pure \& Applied Science University of Tsukuba Tsukuba, 305-8571, Japan

[b] Prof. Y. Moritomo

Graduate School of Pure \& Applied Science

Faculty of Pure \& Applied Science

Tsukuba Research Centre for Energy Materials Science (TREMS)

University of Tsukuba

Tsukuba, 305-8571, Japan

moritomo.yutaka.gf@u.tsukuba.ac.jp

Supporting information for this article is given via a link at the end of the document.
0) and the differences in entropy of the system between reduced and oxidized states. In a battery system, $\Delta S$ consists of components of electrode and that of electrolyte, because the redox process accompanies ion exchange between them. ${ }^{[2]}$

PBAs, denoted as $\mathrm{NaxM}\left[\mathrm{Fe}(\mathrm{CN})_{6}\right]_{y}$ ( $M$ is a transition metal), show three-dimensional (3D) cyano-bridged transition metal network, $-M-N C-F e-C N-M-$, with cubic nanopores of $5 \AA$ on each side. ${ }^{[3]}$ Most of PBAs have face-centered cubic $(F m \overline{3} \mathrm{~m} ; Z=4)$ or trigonal $(R \overline{3} \mathrm{~m} ; Z=3)$ structures. ${ }^{[4]}$ The reduction/oxidization process of the network causes intercalation/deintercalation of $\mathrm{Na}^{+}$ into/from the nanopores. Consequently, PBAs are promising not only as cathode materials for the secondary batteries ${ }^{[5]}$ but also as tertiary battery materials. In addition, PBA exhibits reversible redox reaction even in aqueous solution, ${ }^{[6]}$ which is incombustible and environmentally-friendly. This feature is significant when the materials are used in tertiary batteries, because they do not need wide potential window like the secondary batteries. Shibata et al. ${ }^{[1 \mathrm{~d})]}$ fabricated a tertiary battery made of two kinds of cobalt Prussian blue analogues (PBA) with different $\alpha$, i.e., $\mathrm{Na} \times{ }_{0} \mathrm{Co}\left[\mathrm{Fe}(\mathrm{CN})_{6}\right]_{0.71}$ (NCF71) and $\mathrm{Na} \times{ }_{x} \mathrm{Co}\left[\mathrm{Fe}(\mathrm{CN})_{6}\right]_{0.90}$ (NCF90), and aqueous electrolyte. The NCF71/NCF90 tertiary battery produces electric energy with thermal efficiency $(\eta)$ of $1.0 \%$ between $T_{\mathrm{L}}(=295 \mathrm{~K})$ and $T_{\mathrm{H}}(=323 \mathrm{~K})$. The thermal cyclability of the NCF71/NCF90 tertiary battery, however, is not good. To put the tertiary battery into practical use, improvement of the thermal cycle cyclability is indispensable.

In this paper, we compared the thermal cyclability between the prototypical NCF71/NCF90 tertiary battery and Ni-substituted $\mathrm{Na}{ }_{x} \mathrm{Ni}\left[\mathrm{Fe}(\mathrm{CN})_{6}\right]_{0.68}$ (NNF68)/NCF90 tertiary battery. We found that the thermal cyclability significantly improved in the Ni-substituted tertiary battery. In the NNF68/NCF90 tertiary battery, both the cell voltage $\left[V_{\text {cell }}(40 \mathrm{~K})\right]$ at $\Delta T\left(=T_{\mathrm{H}}-T_{\mathrm{L}}\right)=40 \mathrm{~K}$ and capacity $(Q)$ essentially unchanged up to the 10th thermal cycles.

\section{Results and Discussion}

We first investigate the discharge curves of the NCF90, NCF71, and NNF68 films in aqueous solution containing $17 \mathrm{~mol} / \mathrm{kg}$ $\mathrm{NaClO}_{4}$ with $8.7 \%$ addition of $0.1 \mathrm{~mol} / \mathrm{L} \mathrm{HCl}$. Figure 1 (a), (b), and (c) show the discharge curves of the NCF90, NCF71, and NNF68 films, respectively. In the (a) NCF90 film, the curve shows two plateaus near 1.0 and $0.55 \mathrm{~V}$ vs. $\mathrm{Ag} / \mathrm{AgCl}$, whose feature is the same as that obtained in propylene carbonate (PC) containing $1 \mathrm{M} \mathrm{NaClO}{ }_{4}{ }^{[7]}$ Therefore, the redox site at lower (higher) is $\mathrm{Co}^{3+} / \mathrm{Co}^{2+}\left(\mathrm{Fe}^{3+} / \mathrm{Fe}^{2+}\right)$. In the (b) NCF71 film, the curve shows single plateaus near $0.55 \mathrm{~V}$ vs $\mathrm{Ag} / \mathrm{AgCl}$, which is ascribed to the redox reaction of $\mathrm{Fe}^{3+} / \mathrm{Fe}^{2+[8]}$. Similarly, the curve of in the (c) NNF68 film shows single plateaus near $0.4 \mathrm{~V}$ vs. $\mathrm{Ag} / \mathrm{AgCl}$, which 
is ascribed to the redox reaction of $\mathrm{Fe}^{3+} / \mathrm{Fe}^{2+[9]}$. Importantly, the redox potentials $(V)$ of the lower plateaus are nearly the same among the three films, which is necessary condition to fabricate tertiary battery.
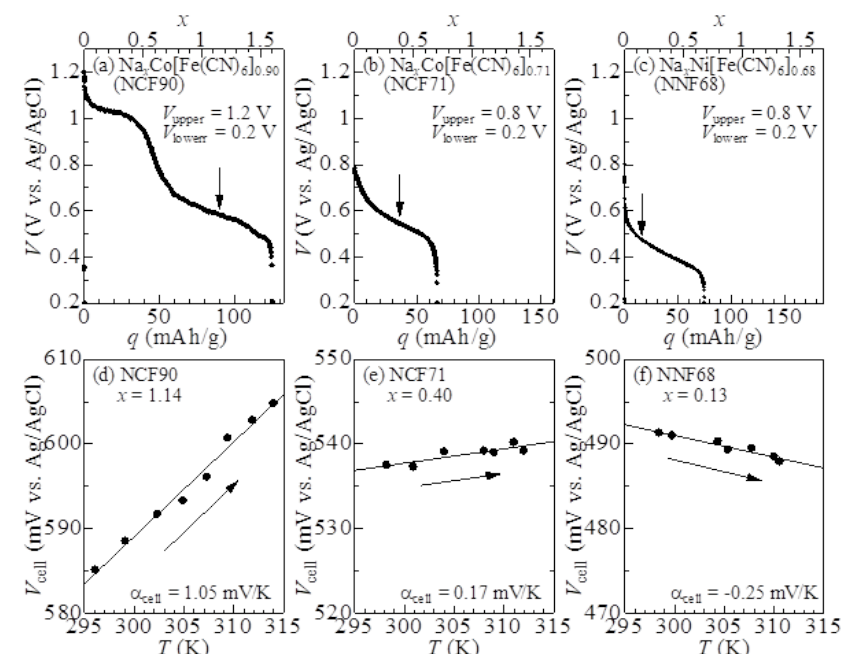

Figure 1. Discharge curves of (a) $\mathrm{Na}_{x} \mathrm{Co}\left[\mathrm{Fe}(\mathrm{CN})_{6}\right]_{0.9}$ (NCF90), (b) $\mathrm{Na} x_{6} \mathrm{Co}\left[\mathrm{Fe}(\mathrm{CN})_{6}\right]_{0.71}$ (NCF71), and (c) $\mathrm{Na} \times \mathrm{Ni}\left[\mathrm{Fe}(\mathrm{CN})_{6}\right]_{0.68}$ (NNF68) films. The current density was $10 \mu \mathrm{A} / \mathrm{cm}^{2}$. The cell voltage $\left(V_{\text {cell }}\right)$ of the (d) NCF90, (e) NCF71, and (f) NNF68 films against temperature $(T)$ in the warming run. Solid straight lines are results of the least-squares fitting. Arrows in (a), (b), and (c) represent the $x$ values, where the $T$-dependences of $V$ were measured.

The temperature coefficient ( $\alpha$ ) of $V$ is expressed as $\alpha=\alpha_{\text {cell }}$ $\alpha_{\text {ref, }}$ where $\alpha_{\text {cell }}$ and $\alpha_{\text {ref }}$ are the coefficient of the cell and referential electrode, respectively. In the present work, the coefficient of the referential electrode $(\mathrm{Ag} / \mathrm{AgCl}$ standard electrode) was $-0.48 \mathrm{mV} / \mathrm{K}^{[10]}$. Figure 1 (d), (e), and (f) show the cell voltage $\left(V_{\text {cell }}\right)$ of the three films against $T$ in the warming run. The $\alpha_{\text {cell }}$ values were evaluated by least-squares fittings, as indicated by solid straight lines. With use of the relation that $\alpha=\alpha_{\text {cell }}+0.48 \mathrm{mV} / \mathrm{K}$, we obtained $\alpha_{\mathrm{NCF} 90}=1.53 \mathrm{mV} / \mathrm{K}$ for NCF90 $(x=1.14), \alpha_{\mathrm{NCF} 11}=0.65 \mathrm{mV} / \mathrm{K}$ for NCF71 $(x=0.40)$, and $\alpha_{\mathrm{NNF68}}=$ $0.23 \mathrm{mV} / \mathrm{K}$ for NNF68 $(x=0.13)$. Strictly speaking, $\alpha$ depends on both the electrode and electrolyte, because the process accompanies exchange of $\mathrm{Na}^{+}$between them. In the oxidized state, $\mathrm{Na}^{+}$dissolves in the electrolyte to form a solvated state, whose entropy strongly depends on the electrolyte. We note that the electrolyte (aqueous solution containing $17 \mathrm{~mol} / \mathrm{kg} \mathrm{NaClO}$ with $8.7 \%$ addition of $0.1 \mathrm{~mol} / \mathrm{L} \mathrm{HCl}$ ) is the same for the three PBA cells. Then, the electrolyte component of $\alpha$ is the same for the three PBAs and cannot explain material dependence of $\alpha$

We emphasize that the coefficient $\left(\alpha_{\mathrm{NCF} 90}=1.53 \mathrm{mV} / \mathrm{K}\right)$ of the NCF90 film is much higher than those in the NCF71 $\left(\alpha_{\mathrm{NCF71}}=0.65\right.$ $\mathrm{mV} / \mathrm{K})$ and NNF68 $\left(\alpha_{\mathrm{NNF68}}=0.23 \mathrm{mV} / \mathrm{K}\right)$ films. The enhanced $\alpha$ in the NCF90 film can be ascribed to the difference in the redox site; the redox site of NCF90 is Co while those of NCF71 and NNF68 are $\mathrm{Fe}$. From a thermodynamically point of view, $\alpha$ is equivalent to $\left(S_{3 \mathrm{~d}}{ }^{\mathrm{di}}-S_{3 \mathrm{~d}}{ }^{\text {tri }}\right) / e$, where $S_{3 \mathrm{~d}}$ di and $S_{3 \mathrm{~d}}{ }^{\text {tri }}$ are the $3 d$-electron configuration entropy of the redox site in the divalent and trivalent states, respectively. $S_{3 \mathrm{~d}}$ is expressed as $k_{\mathrm{B}} \ln W$, where $k_{\mathrm{B}}$ and $W$ $\left(=N_{\text {spin }} N_{\text {orbital }}\right.$, where $N_{\text {spin }}$ and $N_{\text {orbital }}$ are spin and orbital degrees of freedom, respectively) is the Boltzmann constant and number of degenerated electronic configuration. In PBAs, the oxidization process of $\mathrm{Co}^{2+}$ causes spin state transition from high-spin $\mathrm{CO}^{2+}$; $\left.t_{2 g}{ }^{5} e_{g}{ }^{2}\right)$ to low-spin $\left(\mathrm{Co}^{3+} ; t_{2 g}{ }^{6}\right)$ states while the oxidization process of $\mathrm{Fe}^{2+}$ changes the electronic configuration from low-spin $\left(\mathrm{Fe}^{2+}\right.$; $\left.t_{2 g}{ }^{5}\right)$ to low-spin $\left(\mathrm{Fe}^{3+} ; t_{2 g}{ }^{6}\right)$ states. $N_{\text {spin }}$ is expressed as $2 \mathrm{~S}+1$, where $S$ is the total spin quantum number. $N_{\text {orbital }}=3$ in the $t_{2 g}{ }^{5} e_{g}{ }^{2}$ and $t_{2 g}{ }^{5}$ configurations while $N_{\text {orbital }}=1$ in the $t_{2 g}{ }^{6}$ configuration The redox process of $\mathrm{Co}^{2+} / \mathrm{Co}^{3+}$ contributes to $\alpha$ by $0.21 \mathrm{mV} / \mathrm{K}^{[11]}$ while that of $\mathrm{Fe}^{2+} / \mathrm{Fe}^{3+}$ contributes to $\alpha$ by $-0.15 \mathrm{mV} / \mathrm{K}^{[11]}$. Thus, $3 d$-electron configuration entropy of the redox site qualitatively explains why $\alpha$ in NCF90 is larger than those in NCF71 and NCF68.

Figure 2 shows the thermal cycle properties of the $\mathrm{Ni}$ substituted NNF68/NCF90 tertiary battery at $\Delta T\left(=T_{\mathrm{H}}-T_{\mathrm{L}}\right)=40$ $\mathrm{K}$. At the 1 st cycle (black) in the (a) warming process, $V_{\text {cell }}$ linearly increases with the increase in $T$ at a rate of $1.1 \mathrm{mV} / \mathrm{K}$. The rate is comparable to $\alpha_{\text {NCF90 }}-\alpha_{\text {NNF68 }}(=1.3 \mathrm{mV} / \mathrm{K})$. At $T_{\mathrm{H}}, V_{\text {cell }}$ becomes $40 \mathrm{mV}$. In the (b) discharge process at $T_{\mathrm{H}}, V_{\text {cell }}$ linearly decreases to $0 \mathrm{~V}$ with the charge $(q)$. The capacity $(Q)$ is $10 \mathrm{mAh} / \mathrm{g}$, which is $8.2 \%$ of the capacity of NCF90. In the (c) cooling process, $V_{\text {cell }}$ linearly decreases with the decrease in $T$ at a rate of $1.1 \mathrm{mV} / \mathrm{K}$. At $T_{\mathrm{L}}, V_{\text {cell }}$ becomes $-45 \mathrm{mV}$. In the (d) discharge process at $T_{\mathrm{L}}, Q$ is $12.5 \mathrm{mAh} / \mathrm{g}$. The thermal cyclability of the NF68/NCF90 tertiary battery is good; the properties at the 5th (red) and 10th (blue) cycles are essentially the same as that of the 1st cycle (black).


Figure 2. (a) Cell voltage $\left(V_{\text {cell }}\right)$ of the NNF68/NCF90 tertiary battery against temperature $(T)$ measured in the warming run under the open circuit condition at the 1st, 5th, and 10th cycles. Solid straight lines are results of the leastsquares fitting. (b) Discharge curves at $T_{\mathrm{H}}(=323 \mathrm{~K})$ against charge $(q)$. (c) $V_{\text {cell }}$ against $T$ measured in the cooling run under the open circuit condition. Solid straight lines are results of the least-squares fittings. (d) Discharge curves at $T_{\mathrm{L}}$ $(=283 \mathrm{~K})$.

It is rather curious that $Q$ at $T_{\mathrm{L}}$ [Fig.2(d)] is slightly larger than that at $T_{H}[(b)]$. Figure 3 (a) schematically shows the thermal cycle of tertiary battery in the $V_{\text {cell }}-q$ plane. $Q$ is expressed as $Q=$ $\Delta V_{\text {cell }} /\left(\mathrm{d} V_{\text {cell }} / \mathrm{d} q\right)^{[11)]}$, where $\Delta V_{\text {cell }}\left(=\alpha_{\text {cell }} \Delta T\right)$ is the thermally induced 
cell voltage. Note that the sign of $\Delta V_{\text {cell }}$, and hence $Q$, reverses between $T_{\mathrm{H}}$ and $T_{\mathrm{L}}$. If $V_{\text {cell }}$ is stable against time [(a)], $Q$ at $T_{\mathrm{L}}$ should be the same as that at $T_{\mathrm{H}}$. If $V_{\text {cell }}$ is unstable and changes by $\delta(<0)[(b)]$, apparent asymmetry of $Q$ appears between $T_{H}$ and $T_{\mathrm{L}}$. In the initial warming process, $\Delta V_{\text {cell }}(>0)$ and $Q$ is the same as those in the stable case. In the next cooling process, $\Delta V_{\text {cell }}(<0)$ effectively increases by $\delta$. Then, $Q$ at $T_{\mathrm{L}}$ increases by $\delta /\left(\mathrm{d} V_{\text {cell }} / \mathrm{d} q\right)$. We note that the enhancement of $Q$ is observed only at $T_{L}$ because the signs at $T_{\mathrm{H}}$ are opposite between $\Delta V_{\text {cell }}(>0)$ and $\delta(<$ $0)$. Even the voltage fluctuations in the order of several millivolts causes asymmetry of $Q$ because $\Delta V_{\text {cell }}$ is several tens of millivolts. Consistently with these arguments, $\left|\Delta V_{\text {cell }}\right|$ in the cooling process [Figure 2 (c)] is slightly larger than that in the warming process [Figure 2 (a)]. The asymmetry of $Q$ causes gradual variation in the $\mathrm{Na}$ concentration $(x)$ with cycle.

(a) stable $V_{\text {cell }}$

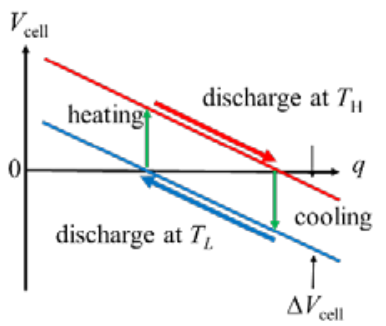

(b) unstable $V_{\text {cell }}$

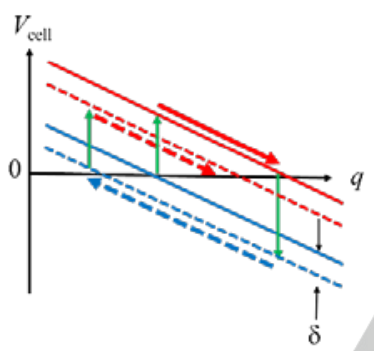

Figure 3 Thermal cycles of tertiary battery with (a) stable and (b) unstable cell voltage $\left(V_{\text {cell. }}\right) \Delta V_{\text {cell }}\left(=\alpha_{\text {cell }} \Delta T\right)$ and $q$ are the thermally induced cell voltage and charge. $\delta$ is temporal variation of $V_{\text {cell. }}$.
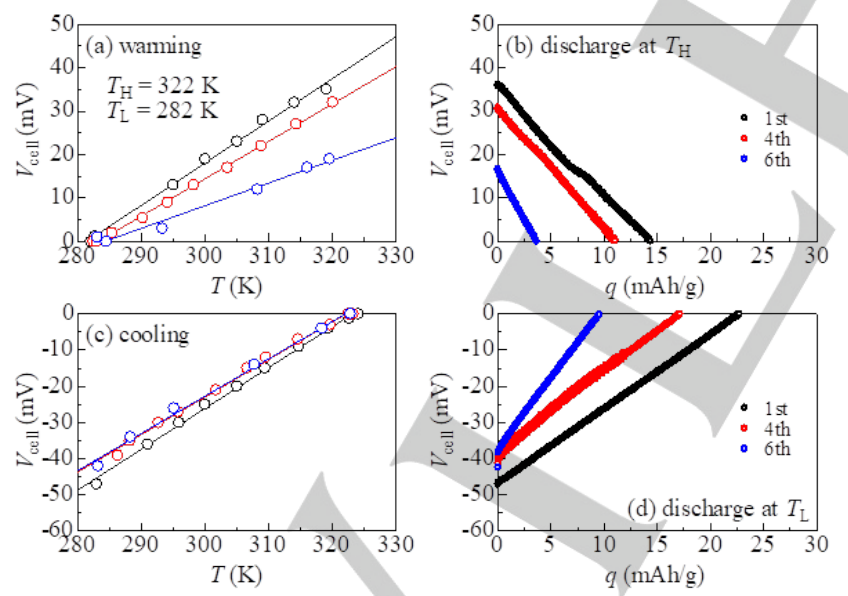

Figure 4. (a) Cell voltage $\left(V_{\text {cell }}\right)$ of the NCF71/NCF90 cell against $T$ measured in the warming run under the open circuit condition at the 1st, 4th, and 6th cycles Solid straight lines are results of the least-squares fitting. (b) Discharge curves at $T_{\mathrm{H}}(=322 \mathrm{~K})$ against charge $(q)$. (c) $V_{\text {cell }}$ against $T$ measured in the warming run under the open circuit condition. Solid straight lines are results of the leastsquares fittings. (d) Discharge curves at $T \mathrm{~L}(=282 \mathrm{~K})$
The good thermal cyclability observed in the Ni-substituted NNF68/NCF90 tertiary battery is in sharp contrast with the poor thermal cyclability of the NCF71/NCF90 tertiary battery. Figure 4 shows the thermal cycle properties of the NCF71/NCF90 tertiary battery at $\Delta T=40 \mathrm{~K}$. In the (a) warming process at the 1st cycle (black), $V_{\text {cell }}$ linearly increases with the increase in $T$ at a rate of $1.0 \mathrm{mV} / \mathrm{K}$. The rate is comparable to $\alpha_{\mathrm{NCF} 90}-\alpha_{\mathrm{NNF68}}(=0.9 \mathrm{mV} / \mathrm{K})$. The rate, however, steeply decreases with cycle number; $0.8 \mathrm{mV} / \mathrm{K}$ at the 4 th cycle (red) and $0.4 \mathrm{mV} / \mathrm{K}$ at the 6 th cycle (blue). In the (b) discharge at $T_{\mathrm{H}}$ at the 1 st cycle (black), $Q$ is $14.3 \mathrm{mAh} / \mathrm{g}$, which is $11.4 \%$ of the capacity of NCF90. Q, however, steeply decreases with cycle number; $11.0 \mathrm{mAh} / \mathrm{g}$ at the 4 th cycle (red) and $3.6 \mathrm{mAh} / \mathrm{g}$ at the 6 th cycle (blue).

Figure 5 shows (a) $Q$ and (b) cell voltage $\left[V_{\text {cell }}(40 \mathrm{~K})\right]$ at $\Delta T=$ $40 \mathrm{~K}$ against cycle number. In the NNF68/NCF90 tertiary battery (open red circles), both $Q$ and $V_{\text {cell }}(40 \mathrm{~K})$ essentially unchanged up to the 10th thermal cycle. In the NCF71/NCF90 tertiary battery (filled blue circles), however, $Q$ steeply decreases with cycle number at a rate of $-11 \% / c y c l e$. In addition, $V_{\text {cell }}(40 \mathrm{~K})$ decreases with cycle number at a rate of $-7 \% /$ cycle. The substitution of $\mathrm{Ni}$ for Co in the NCF71 film significantly improves the deteriorations of the NCF71/NCF90 tertiary battery. In other words, the bad thermal cyclability of the NCF71/NCF90 cell is originated in the NCF71 film, not in the NCF90 film.

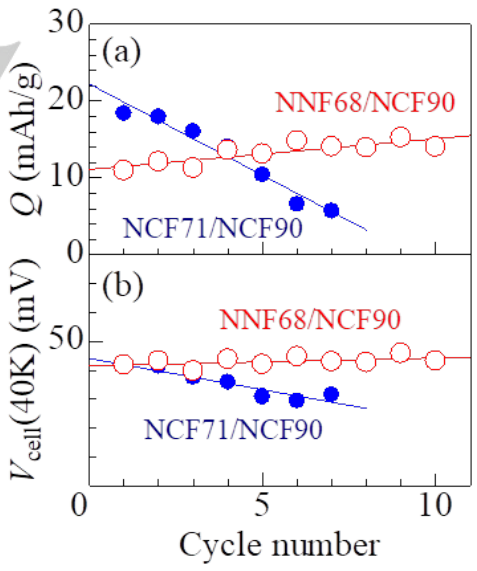

Figure 5. (a) Capacity $(Q)$ and (b) cell voltage $\left[V_{\text {cell }}(40 \mathrm{~K})\right]$ at $\Delta T=40 \mathrm{~K}$ in the NNF68/NCF90 (open red circles) and NCF71/NCF90 (filled blue circles) tertiary batteries against cycle number. Average values of the warming and cooling runs are plotted. Solid straight lines are results of the least-squares fittings.

Figure 6 shows discharge curves of the (a) NCF71 and (b) NNF68 films against cycle number at $T_{\mathrm{L}}(=283 \mathrm{~K}$; blue $)$ and $T_{\mathrm{H}}(=$ $323 \mathrm{~K}$; red), respectively. At $T_{\mathrm{L}}$, no trace of the capacity deterioration was observed in both the films up to the 10th cycle. At $T_{\mathrm{H}}$, however, serious capacity deterioration was observed in the NCF71 film [Figure 5 (a)]. The capacity at the 2nd (3rd) cycle is $57 \%(12 \%)$ of that at the 1 st cycle. Such a capacity deterioration of the NCF71 film causes the poor thermal cyclability of the NCF71/NCF90 tertiary battery. The origin of the capacity deterioration is perhaps the cracks formation in the particles, since the NCF71 films sometimes peeled off during the washing 
after the cyclability test. The substitution of $\mathrm{Ni}$ for Co significantly improves the capacity deterioration [Figure 6 (b)] and causes the good thermal cyclability of the NNF68/NCF90 tertiary battery (Figure 5). Similarly, Xie et al. ${ }^{[5 i)]}$ reported that cyclability of $\mathrm{Na}_{2} \mathrm{Co}_{1-2} \mathrm{Ni}_{2}\left[\mathrm{Fe}(\mathrm{CN})_{6}\right]$ as cathode material for the sodium ion secondary battery in ethylene carbonate (EC) / diethyl carbonate (DEC) containing $1 \mathrm{M} \mathrm{NaPF}_{6}$ becomes better with the increase in the Ni concentration $(z)$. The capacities at the 100th cycle are $49.2 \%, 89.5 \%$, and $91.7 \%$ of those at the first cycle at $z=0.0$, 0.5 , and 1.0 , respectively.
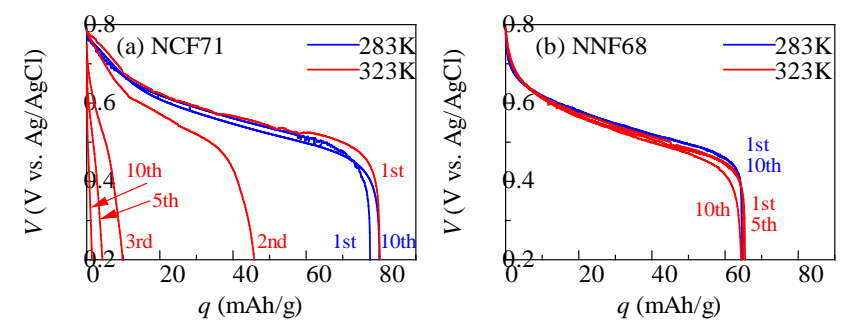

Figure 6. Discharge curves of the (a) NCF71 and (b) NNF68 films up to the 10th cycle. The blue and red curves represent the data measured at $T \mathrm{~L}(=283 \mathrm{~K})$ and $T_{\mathrm{H}}(=323 \mathrm{~K})$, respectively. The current density was $10 \mu \mathrm{A} / \mathrm{cm}^{2}$. deficiencies and large unit cell size causes the highly porous structure, which is amenable for the crack formation during the chare/discharge process at $T_{\mathrm{H}}$. On the other hands, the NNF68 film with lower crystallinity and smaller unit cell size is robust against the crack formation during the chare/discharge process.

\section{Conclusions}

We compared the thermal cyclability between the prototypical NCF71/NCF90 tertiary battery and Ni-substituted NNF68/NCF90 tertiary battery. We found that the thermal cyclability significantly improved in the Ni-substituted tertiary battery. Both the cell voltage $\left[V_{\text {cell }}(40 \mathrm{~K})\right]$ at $\Delta T=40 \mathrm{~K}$ and capacity $(Q)$ essentially unchanged up to the 10th thermal cycles. Our experiment reveals that the poor cyclability of the NCF71 film at $T_{\mathrm{H}}(=323 \mathrm{~K})$ is responsible for the poor thermal cyclability of the NCF71/NCF90 tertiary battery. Present work indicates that tertiary batteries are one of the promising energy harvesting devices.

\section{Supporting Information and Summary}

Scanning Electron microscope (SEM) images and X-ray diffraction (XRD) patterns of the as-grown NCF71, BCF90, and NNF68 films are shown.

Table 1. Crystallinity, density of $\left[\mathrm{Fe}(\mathrm{CN})_{6}\right]$ deficiency, and unit cell size (a) of the NCF71, NCF90, and NNF68 films.

\begin{tabular}{cccc}
\hline \multirow{2}{*}{ Film } & crystallinity & density of $\left[\mathrm{Fe}(\mathrm{CN})_{6}\right]$ deficiency & $\mathrm{a}(\mathrm{nm})$ \\
\hline NCF71 & High & $29 \%$ & $\sim 1.03^{[8]}$ \\
NCF90 & High & $10 \%$ & $<1.02^{[7]}$ \\
NNF68 & Low & $68 \%$ & $\sim 1.02^{[9]}$ \\
\hline
\end{tabular}

Here, we consider the necessary conditions and possible mechanism for the crack formation in PBA particles. Figure S1 shows scanning electron microscope (SEM) image of the NCF71. NCF90, and NNF68 films. The NCF90 and NCF71 films consists of crystalline particles about $100 \mathrm{~nm}$ in diameter, while the NNF68 film consists of granular particles with low crystallinity. Figure S2 shows X-ray diffraction pattern (XRD) of the NCF71, NCF90, and NNF68 films. The diffraction peaks of the NNF68 film is much broader than those of the NCF71 and NCF90 films, indicating smaller domain size $(\sim 20-70 \mathrm{~nm})$ in the NNF68 film. On the other hand, the unit cell size (a) of NCF90 $0^{[7]}$ and NNF68 ${ }^{[9]}$ is less than $1.02 \mathrm{~nm}$ in the entire region of $x$, and is smaller than that $(-$ $1.03 \mathrm{~nm}^{[8]}$ in the entire region of $x$ of NCF71. We summarized In Table 1 particle crystallinity and a of the NCF71, NCF90, and NNF68 films, together with the density of $\left[\mathrm{Fe}(\mathrm{CN})_{6}\right]$ deficiencies. The NCF71 film, whose cyclability is bad due to crack formation, has higher crystallinity, higher-density of the $\left[\mathrm{Fe}(\mathrm{CN})_{6}\right]$ deficiency, and larger unit cell size. It is reasonable that the high crystallinity makes the crack formation easier. In addition, the high-density Fe

\section{Acknowledgements}

This work was supported by JSPS KAKENHI (Grant Number JP17H01137 and 19J12284), the Japan Prize Foundation, and a joint research with Focus Systems Corporation. The elementary analyses were performed at the Chemical Analysis Division, Research Facility Center for Science and Engineering, University of Tsukuba.

I. Takahara fabricated the NNF68/NCF90 and NCF71/NCF90 tertiary batteries and measured thermal cyclability on each batteris. Y. Fukuzumi characterized the PBA films. T. Shibata and $\mathrm{Y}$. Moritomo planed the research and wrote the manuscript.

Keywords: energy harvesting • Prussian blue analogues • substitution effect $\bullet$ tertiary battery $\bullet$ thermal cyclability

[1] a) S. W. Lee, Y. Yang, H.-W. Lee, H. Ghasemi, D. Kraemer, G. Chen, Y. Cui, Nat. Commun. 2014, 5, 3942, b) Y. Yang, S. W. Lee, H. Ghasemi, J. Loomis, X. Li, D. Kraemer, G. Zheng, Y. Cui, G. Chen, PNAS 2014 111, 17011-17116, c) J. Wang, S.-P. Feng., Y. Yang, N. Y. Hau, M. Munro, E. Ferreira-Yang, G. Chen, Nano Lett. 2015, 15, 5784-5790, d) T. Shibata, Y. Fukuzumi, W. Kobayashi, Y. Moritomo, Appl. Phys. Express 2018, 11, 017101, e) Y. Fukuzumi, K. Amaha, H. Niwa, W Kobayashi, Y. Moritomo, Energy Technol. 2018, 6, 1865-1870, f) T. Shibata, Y. Fukuzumi, Y. Moritomo, Sci. Reps. 2018, 8, 14784

[2] a) Y. Fukuzumi, Y. Hinuma, Y. Moritomo, J. Phys. Soc. Jpn. 2018, 87, 055001, b) Y. Fukuzumi, Y. Hinuma, Y. Moritomo, AIP Adv., 20186 065021. 
[3] a) H. J. Buser, D. Schwarzenbach, W. Petter, A. Ludi, Inorg. Chem. 1977, 16, 2704-2710, b) F. Herren, P. Fischer, A. Ludi, W. Halg, Inorg. Chem. 1980, 19, 956-959.

[4] H. Niwa, W. Kobayashi, T. Shibata, H. Nitani, Y. Moritomo, Sci. Reps. 2017, 7, 13225.

[5] a) Y. Lu, L. Wang, J. Cheng, J. B. Goodenough, Chem. Commun. 2012 48, 6544-6546, b) T. Matsuda, M. Takachi, Y. Moritomo, Chem. Commun. 2013, 49, 2750-2752, c) M. Takachi, T. Matsuda, Y. Moritomo, Appl. Phys. Express 2013, 6, 025802, d) Y. You, X.-L. Wu, Y.-X. Yin, Y.-G. Guo, J. Mater. Chem. A, 2013, 1, 14061-14065, e) D. Yang, J. Xu, X.-Z. Liao, Y.-S. He, H. Liu, Z.-F. Ma, Chem. Commun. 2014, 50, 13377-13380 f) H. W. Lee, R. Y. Wang, M. Pasta, S. W. Lee, N. Liu, Y.Cui, Nat. Commun. 2014, 5, 5280, g) L. Wang, J. Song, R. Q. Qiao, L. A. Wray, M. A. Hossain, T.-D. Chung, W. Yang, Y. Lu, D. Evans, J,-J, Lee, S. Vail, X Zhao, M. Nishijima, S. Kakimoto, J. B. Goodenough, J. Am. Chem. Soc. 2015, 137, 2548-2554, h) S. Yu, Y. Li, Y. Lu, B. Xu, Q. Wang, M. Yan, Y. A. Jiang, J. Power Sources, 2015, 275, 45-49, i) M. Xie, M. Xu, Y. Huang, R. Chen, X. Zhang, L. Li, F. Wu, Electrochem. Commun. 2015, 59, 91 94, j) Y. Moritomo, S. Urase, T. Shibata, Electrochim. Acta 2016, 210, 963-969.
[6] a) C. D. Wessells, S. V. Peddada, R. A. Huggins, Y. Cui, Nano Lett. 2011 11, 5421-5425, b) C. D. Wessells, M. T. McDowell, S. V. Peddada, M Pasta, R. A. Huggins, Y. Cui, ACS Nano. 2012, 6, 1688-1694, c) X. Wu, Y. Luo, M. Sun, J. Qian, Y. Cao, X. Ai, H. Yang, Nano Energy 2015, 13, 117-123, d) M. Pasta, R. Y. Wang, R. Ruffo, R. Qiao, H.-W. Lee, B. Shyam, M. Guo, Y. Wang, L. A. Wray, W. Yang, M. F. Toney, Y. Cui, J. Mater. Chem. A, 2016, 4, 4211-4223, e) K. Nakamoto, R. Sakamoto, M. Ito, A. Kitajou, S. Okada, Electrochemistry 2016, 85, 179-185, f) W. Li, F Zhang, X. Xiang, X. Zhang, J. Phys. Chem. C 2017, 121, 27805-27812.

[7] M. Takachi, T. Matsuda, Y. Moritomo, Jpn. J. Appl. Phys. 2013, 52, 090202.

[8] F. Nakada, H. Kamioka, Y. Moritomo, J. E. Kim, M. Takata, Phys. Rev. B 2008, 77, 224436.

[9] T. Shibata, F. Nakada, H. Kamioka, Y. Moritomo, J. Phys. Soc. Jpn. 2008 77,104714

[10] R. G. Bates and V. E. Bower, J. Res. Natl. Bur. Stand., 1954, 53, 283290.

[11] H. Iwaizumi, Y. Fujiwara, Y. Fukuzumi, Y. Moritomo, Dalton Trans. 2019, 48, 1964-1968. 


\section{Entry for the Table of Contents}

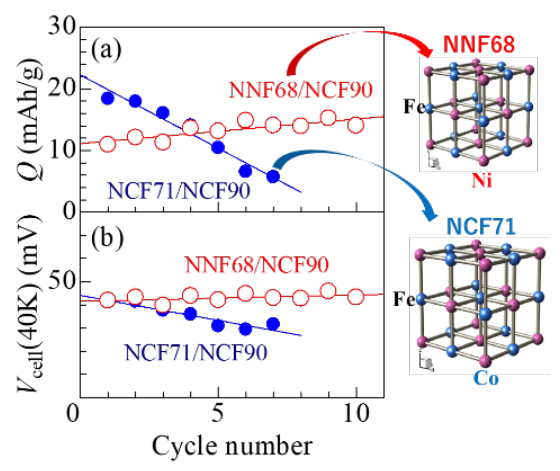

Tertiary battery is charged by the environmental heat and is a promisingenergy harvesting device for the loT society. The thermal cyclability is not good in the prototypical $\mathrm{Na}_{x} \mathrm{Co}\left[\mathrm{Fe}(\mathrm{CN})_{6}\right]_{0.71}$ (NCF71)/ $\mathrm{Na}{ }_{x} \mathrm{Co}\left[\mathrm{Fe}(\mathrm{CN})_{6}\right]_{0.90}$ (NCF90) tertiary battery. Here, we significantly improved the thermal cyclability of the tertiary battery with using Ni-substituted $\mathrm{Na} \times \mathrm{Ni}\left[\mathrm{Fe}(\mathrm{CN})_{6}\right]_{0.68}(\mathrm{NNF68)}$. The improvement is ascribed to poorer crystallinity and smaller unit cell size of the NNF68 film. 